\title{
A View From the South on the Changing Coastal and Estuarine Environments
}

\author{
Paulina Martinetto $^{1}$ - Oscar Iribarne ${ }^{1}$
}

Received: 28 January 2015 /Revised: 26 May 2015 / Accepted: 30 May 2015 / Published online: 18 June 2015

(C) Coastal and Estuarine Research Federation 2015

During November 2012, Coastal and Estuarine Research Federation (CERF) celebrated its first international conference in Mar del Plata, Argentina. The conference title was The Changing Coastal \& Estuarine Environment: a Comparative Approach, with emphasis on north-south comparisons as an overarching theme. It was the first effort by CERF to expand its range of collaborations and enlarge the scope of its international reach. The meeting was conceived as a way to develop and compare estuarine questions across a north-south geographic range, encourage comparisons, and foster networking. This dedicated issue of Estuaries and Coasts compiles a selection of articles derived from talks presented in the conference. The collection of contributions, although by no means a complete list of the program of the conference, summarizes some of the main issues and discussions that arose during the conference.

A most unfortunate turn of events took place as the conference was being planned. The passing of Scott Nixon a tribute to a major contributor, who would have surely been invited to the meeting, should be an additional conference theme. A dedicatory In Memoriam hence opens this special theme issue. Our community's debt to Scott is highlighted further in two papers of this issue. The many

Communicated by: Wayne S. Gardner

Paulina Martinetto

pmartin@mdp.edu.ar

Laboratorio de Ecología, Instituto de Investigaciones Marinas y Costeras (IIMyC) Consejo Nacional de Investigaciones Científicas y Técnicas (CONICET), Universidad Nacional de Mar del Plata, Rodriguez Peña 4046 piso 1, B7602GSD Mar del Plata, Argentina ideas suggested by Scott across the years that influenced and invigorated work on land-coastal couplings are traced (Valiela and Bartholomew 2014). The closing paper reviews and expands Scott's notions on estuarine and coastal ecosystem recovery, identifies underlying paradigms of recovery, and discusses restoration efforts in conditions with changing baselines (Duarte et al. 2013a).

The essential concern of the conference was to furnish updates on north-south comparisons with regard to six core issues: (1) changing baselines of populations, (2) land-sea couplings in rapidly changing environments, (3) fisheries exploitation, (4) impacts of UV on coastal waters, (5) acidification of coastal waters, and (6) warming climate effects on freshwater use on land and hydrodynamics of estuaries. Plenary speakers led special sessions and summarized the state of knowledge of these topics within coastal environments affected by local, regional, or global impacts by humans, with emphasis in northsouth comparisons in the Americas.

It was challenging to find north-south counterpart comparison of several of the core issues. In some cases, such as changing baseline populations, it was difficult to find counterparts given that there are very few cases with long term records in the south where changes in coastal populations can be identified, and where anthropogenic effects are separated from changes in natural cycles. For other core issues, scientific studies were not available for both hemispheres. The present compilation of papers presented in this theme issue mirrors such differences.

A north-south comparison paper shows a contrasting sensitivity of biota from the southern and the northern hemispheres to UV-B radiation. Although UV radiation is higher in the southern high latitude regions, research effort in this topic remains focused in northern sites (Agustí et al. 2014). 
Further perspectives on this topic are provided with research on UV effects conducted in South America (Helbling et al. 2013; Gouveia et al. 2015).

Acidification of coastal waters is a topic developed mostly by research performed in the northern hemisphere. In coastal areas, acidification processes are often related to eutrophication events rather than increased atmospheric $\mathrm{CO}_{2}$ (Duarte et al. 2013b), although upwelling areas may experiment a combination of both drivers. In this issue, experimental results obtained in the Central Chilean coast highlight the high tolerance of coastal organisms to changes in $\mathrm{pH}$, with local minor negative effects associated with river discharges (Vargas et al. 2014). This article is among the first publications investigating coastal acidification effects in South America.

Research information about salt marshes has been dominated historically by published results from North America and Europe. In this issue, salt marsh results collected over the past three decades from the Southwest Atlantic coast of Argentina are compared to results from northern salt marsh ecology studies (Alberti et al. 2014). The authors provide an excellent example of how generalities in ecological theory based on extensive (over 100 years) research carried out in northern salt marshes may not apply to the functioning of salt marshes located elsewhere. In addition, this review shows how taking a broad perspective can move forward and challenge accepted ecological theory and promote new hypotheses.

The article on land-sea coupling points out the interplay between local contingencies, i.e., human pressures, on land and global-scale forcing (Valiela and Bartholomew 2014). The presented case histories from Waquoit Bay, MA, and the Pacific coast of Panama illustrate the importance of considering external global scale, as well as local control processes, in ecosystem studies. The article emphasizes the contributions of Scott Nixon, who first recognized the need to consider climate change as a potential driver of eutrophication on a large scale together with local and regional processes (Nixon 2009).

The differences exemplified and supported by the articles compiled in this thematic issue of Estuaries and Coasts arose from the presentations and discussions in the conference. We highlight the importance of supporting international conferences to promote exchange of knowledge, opinions, and perspectives among colleagues, which in turn, propitiate development of new hypothesis. We must be careful about generalizations based on studies of our local region, however competent. This approach is analogous to the old saying about the wellbased theory that "all swans are white", supported by ever so numerous northern observations. The theory failed completely when someone went to Australia and ran into black swans (or we might add, if they had bothered to reach Argentina and seen the many black-necked swans!). Ecological theory has been mainly developed in the Northern Hemisphere, and the development of paradigms of the functioning of coastal and estuarine ecosystems may be influenced by these differences. Thus, some caution should be taken when paradigms derive from regionally restricted scientific evidence.

Acknowledgments Special thanks to Bob Christian for co-organizing the conference with us on behalf of the CERF Board; to Walter Boynton and Susan Williams, CERF presidents, who gave us the opportunity to organize this conference in Mar del Plata; and to Ivan Valiela for his persistent effort towards developing CERF international conferences, and holding this first one in Mar del Plata, Argentina. We thank all the authors who agreed to submit papers to this thematic issue.

\section{References}

Agustí, S., M. Llabrés, B. Carreja, M. Fernández, and C.M. Duarte. 2014. Contrasting sensitivity of marine biota to UV-B radiation between southern and northern hemispheres. Estuaries and Coasts. doi:10. 1007/s12237-014-9790-9.

Alberti, J., P. Daleo, E. Fanjul, M. Escapa, F. Botto, and O. Iribarne. 2014. Can a single species challenge paradigms of salt marsh functioning? Estuaries and Coasts. doi:10.1007/s12237-014-9836-z.

Duarte, C.M., A. Borja, J. Cartensen, M. Elliot, D. Krause-Jensen, and N. Marbà. 2013a. Paradigms in the recovery of estuarine and coastal ecosystems. Estuaries and Coasts. doi:10.1007/s12237-013-97509.

Duarte, C.M., I.E. Hendriks, T.S. Moore, Y.S. Olsen, A. Steckbauer, L. Ramajo, J. Cartensen, J.A. Trotter, and M. McCulloch. 2013b. Is ocean acidification an open-ocean syndrome? Understanding anthropogenic impacts on seawater pH. Estuaries Coasts 36: 221-236.

Gouveia, G.R., G.S. Trindade, L.E. Maia Nery, and J.H. Muelbert. 2015. UVA and UVB penetration in the water column of a Southwest Atlantic warm temperate estuary and its effects on cells and fish larvae. Estuaries and Coasts. doi:10.1007/s12237-015-9996-5

Helbling, E.W., A.T. Banaszak, and V.E. Villafañe. 2013. Differential responses of two phytoplankton communities from the Chubut river estuary (Patagonia, Argentina) to the combination of UVR and elevated temperature. Estuaries and Coasts. doi:10.1007/s12237-0139752-7.

Nixon, S.W. 2009. Eutrophication and the macroscope. Hydrobiologia 629: 5-19.

Valiela, I., and M. Bartholomew. 2014. Land-Sea coupling and globaldriven forcing: following some of Scott Nixon's challenges. Estuaries and Coasts. doi:10.1007/s12237-014-9808-3.

Vargas, C.A., V.M. Aguilera, V. San Martín, P.H. Manríquez, J.M. Navarro, C. Duarte, R. Torres, M.A. Lardies, and N.A. Lagos. 2014. $\mathrm{CO}^{2}$-driven ocean acidification disrupts the filter feeding behavior in Chilean gastropod and bivalve species from different geographic localities. Estuaries and Coasts. doi:10.1007/s12237-0149873-7. 